ZOOLOGIA 30 (2): 211-216, April, 2013

http://dx.doi.org/10.1590/S1984-46702013000200011

\title{
Determination of larval instars in Chironomus sancticaroli (Diptera: Chironomidae) using novel head capsule structures
}

\author{
Vinicius S. Richardi ${ }^{1}$, Débora Rebechi' ${ }^{1}$, José M. R. Aranha² \& Mário A. Navarro-Silva1,3 \\ ${ }^{1}$ Laboratório de Entomologia Médica e Veterinária, Departamento de Zoologia, Setor de Ciências Biológicas, Universidade \\ Federal do Paraná. Caixa Postal 19020, 81531-980 Curitiba, PR, Brazil. \\ 2 Laboratório de Ecologia de Rios, Universidade Federal do Paraná, Campus Palotina. 85950-000 Palotina, PR, Brazil. \\ ${ }^{3}$ Corresponding author. E-mail: mnavarro@ufpr.br
}

\begin{abstract}
Determining the age composition of a population is important when conducting ecological, taxonomic and environmental assessments. Morphometric measurements of the head capsule, especially the length and width, are widely used in the identification of insect instars, but alternative ways for determining the age of insects can expand the options for the analysis of field and laboratory populations. This study evaluated the morphometry of the antennae, mandibles, mentum and ventromental plates to discriminate among the four larval instars of Chironomus sancticaroli Strixino \& Strixino, 1981 . The larvae were reared in the laboratory under constant temperature $\left(25^{\circ} \mathrm{C}\right)$ and photoperiod of $12 / 12$ hours for 19 days, with a supply of food. Fifteen larvae were removed randomly every day, cleared in $\mathrm{KOH}$, and slide-mounted, and had the antennae, mandibles, mentum and ventromental plates measured. The dimensions of the four structures studied allowed us to statistically distinguish each of the four larval instars. The data fit an exponential equation according to the Brooks-Dyar rule, which allows an estimate of the larval instar of specimens collected in the field, even when development takes place under different conditions. The duration of each instar was also obtained from our data, and showed an overlap of instars during development.
\end{abstract}

KEY WORDS. Growth rate; head capsule; instars; morphometry.

Among the benthic macroinvertebrates, Chironomidae are noteworthy for their wide geographical distribution and abundance. They occupy a wide range of ecological niches due to their physiological plasticity, and their role in nutrient cycling and energy flow in aquatic ecosystems (Covich et al. 1999). The biological characteristics of chironomids enable their use in different types of studies, such as population dynamics (BEAudouin et al. 2012), ecological interactions (Frouz et al. 2009, Henriques-Oliveira \& Nessimian 2009), taxonomy (TrivinhoStrixino 2011), as indicators of environmental impact (Di Veroli et al. 2012) and as test-organisms in toxicity bioassays (U.S. Environmental Protection Agency 2000). In order to implement those studies, it is important to ascertain the age composition of the population under study, which depends on the ability to discriminate among the larval instars (Di Veroli et al. 2008).

The development of immature Chironomidae can be influenced by various environmental factors such as temperature, photoperiod, availability and quality of food (STRIXINO \& Trivinho-Strixino1985, Canteiro \& Albertoni 2011), population densities (McLachlan 1977, KaJaK \& Prus 2001 ) and interactions with chemicals (Di Veroli et al. 2012). However, even under different temperature regimes, it is possible to discriminate among instars using the dimensions of the head capsule (STEVENS 1993).
Morphometry is a widely used tool in the determination of insect instars (DALY 1985). The dimensions most commonly used to determine the number of larval instars is the width (ECole et al. 1999, Silva et al. 2008) or the length of the head capsule from ventral view (McCauley 1974, Trivinho-Strixino \& STRIXINo 1982). However, the compression caused by the process of slide mounting changes some of the head's measurements (Ford 1959). In Chironomidae, a number of studies have been able to ascertain the number of instars based mainly on the length of the head capsule from ventral view (Ford 1959, McCauley 1974, Trivinho-Strixino \& Strixino 1982, Stevens 1993), but the antennae, mandibles (Ford 1959) and mentum (Frouz et al. 2002) have also been used for this purpose.

With the intention to verify whether the dimensions of other structures beyond the length of the head capsule from ventral view assist in the identification of larval instars of Chironomidae, we endeavored to determine the instars of Chironomus sancticaroli using morphometric measurements of the antennae, mandibles, mentum and ventromental plates.

\section{MATERIAL AND METHODS}

The organisms were obtained from a colony maintained in the Laboratory of Medical and Veterinary Entomology, Uni- 
versidade Federal do Paraná (UFPR). This colony has approximately 20 generations in the laboratory and has been maintained following the protocol of MAIER et al. (1990), with changes in temperature $\left(25^{\circ} \mathrm{C} \pm 2^{\circ} \mathrm{C}\right)$, photoperiod (12 hours light/12 hours dark) and humidity (70\% $\pm 10 \%)$.

Egg masses containing 500-1000 eggs were placed in trays with four liters of water and $0.1 \mathrm{~g}$ of macerated TetraMin feed per week. When the larvae started to hatch, we removed 15 individuals randomly every day. We did this until the last larvae reached the pupal stage, about 19 days later. The larvae were stored in vials which were labeled with the date, in 70\% alcohol.

For the semipermanent mounting, we removed each larva from the $70 \%$ alcohol and placed it in $6 \%$ potassium hydroxide $(\mathrm{KOH})$ at $50^{\circ} \mathrm{C}$. Larvae of the first, second, third and fourth instars were cleared, respectively, for 30 minutes, two, four and six hours. Subsequently, the larvae were mounted on slides with the ventral side facing up, with glycerin and absolute ethanol in a 3:1 ratio and sealed with nail polish.

The structures used for morphometric analysis were: antennae, mandibles, mentum and ventromental plates. The length of head capsule from ventral view was used to compare the results. Linear measurements from fixed points were taken directly using a minute reading eyepiece coupled with an optical microscope, performing the required conversions (Figs 15). At least ten larvae were measured each day, totaling 240 measurements per structure at the end of the 19 days of the experiment. Measurements were not obtained only from larvae in their first day, because the recently hatched larvae remained in the mucilaginous substance of the ovigerous mass, feeding. This made it impossible to capture them for analysis. The voucher specimens were deposited in the Coleção Entomológica Padre Jesus Santiago Moure (DZUP), Universidade Federal do Paraná, Curitiba, Paraná, Brazil.

Analysis of variance (One-way ANOVA) using metric data was generated and the Tukey's post test was applied to verify the significance of the differences in measurements among the instars. To estimate the duration of instars, we plotted the days ( $\mathrm{x}$ axis) and length of the structure (y axis) on a graph. To ascertain whether the growth of the structures is consistent with the Brooks-Dyar rule (DALY 1985), the average size of the structures were converted to values of $\ln$, and a linear regression was performed with respect to the instar, obtaining an exponential equation ( $\mathrm{x}=$ measure of structure $\mathrm{mm}$ and $\mathrm{y}=$ number instar) that makes it possible to estimate the instar of the insect using the size of a sclerotized structure (DYAR 1890, Hutchinson \& Tongring 1984). The average rate of growth was computed as a ratio, which was calculated from the measurement of a structure of a given instar divided by the measurement of the same structure in the previous instar; then, an average was calculated between the three ratios obtained for each structure.
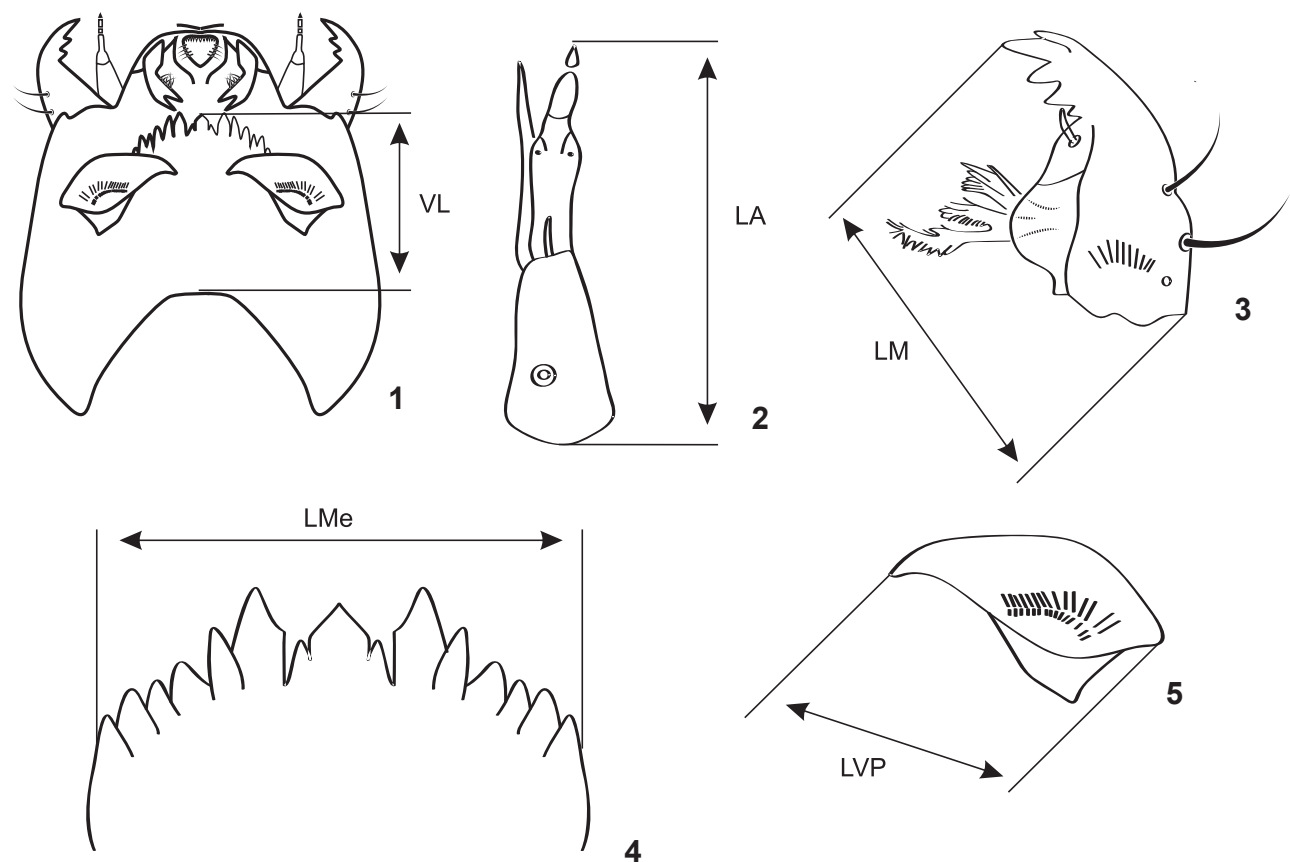

Figures 1-5. Structures and the method for measurement used to determine instars for immature of Chironomus sancticaroli: (1) head capsule; (2) antennae; (3) mandibles; (4) mentum; (5) ventromental plates. (LA) Length of the antennae, (LM) length of the mandible, (LME) length of the mentum, (LVP) length of the ventromental plates, (VL) length of head capsule from ventral view. 


\section{RESULTS}

The measurements of the antennae, mandibles, mentum and ventromental plate allowed us to distinguish the four larval instars without overlap of values (Table I). Significant differences were revealed by the analysis of variance (One-way ANOVA, p < 0.001) (Figs 6-10).

The duration of each instar, taking into account the measurements of all structures, each day, was similar for the $1^{\text {st }}, 2^{\text {nd }}, 3^{\text {rd }}$ and $4^{\text {th }}$ instars, respectively, from the first to the third day of the cycle, the fourth to the fifth day, the fifth to the eighth day, and the sixth to the $19^{\text {th }}$ day, indicating that, from daily measurement of any structure, we can be obtain the duration of the instars under laboratory conditions.

The measures of central tendency and dispersion of the values of the structures of the head capsule have enabled us to obtain exponential equations, showing that growth in $C$. sancticaroli follows a pattern of geometric progression according to the Brooks-Dyar rule. It is possible, from the measurement of an structure, to identify the stage of the immature instars of this species in laboratory and field conditions, as well as to obtain the average rate of growth of instars (Table II).

\section{DISCUSSION}

We were able to determine that $C$. sancticaroli has four larval instars, and that those instars can be identified using morphometric data of five different head capsule structures. The occurrence of four instars is probably universal for chironomids (OLIVER 1971), having been reported for Tanypodinae, Diamesinae, and Orthocladiinae and Chironominae (Ford 1959, Thienemann 1954, Canteiro \& Albertoni 2011). However, there are records of smaller and greater numbers of instars in Orthocladiinae (Ford 1959) and of five instars in Tanypodinae (STYCZyNSKI \& Rakusa-Suszczwski 1963).

The antennae, mandibles, mentum and ventromental plates of C. sancticaroli undergo morphological changes during ontogeny. These changes, however, do not influence the dimensions of these structures. Furthermore, we suggest an alternative way to ascertain the larval instars: the variation in
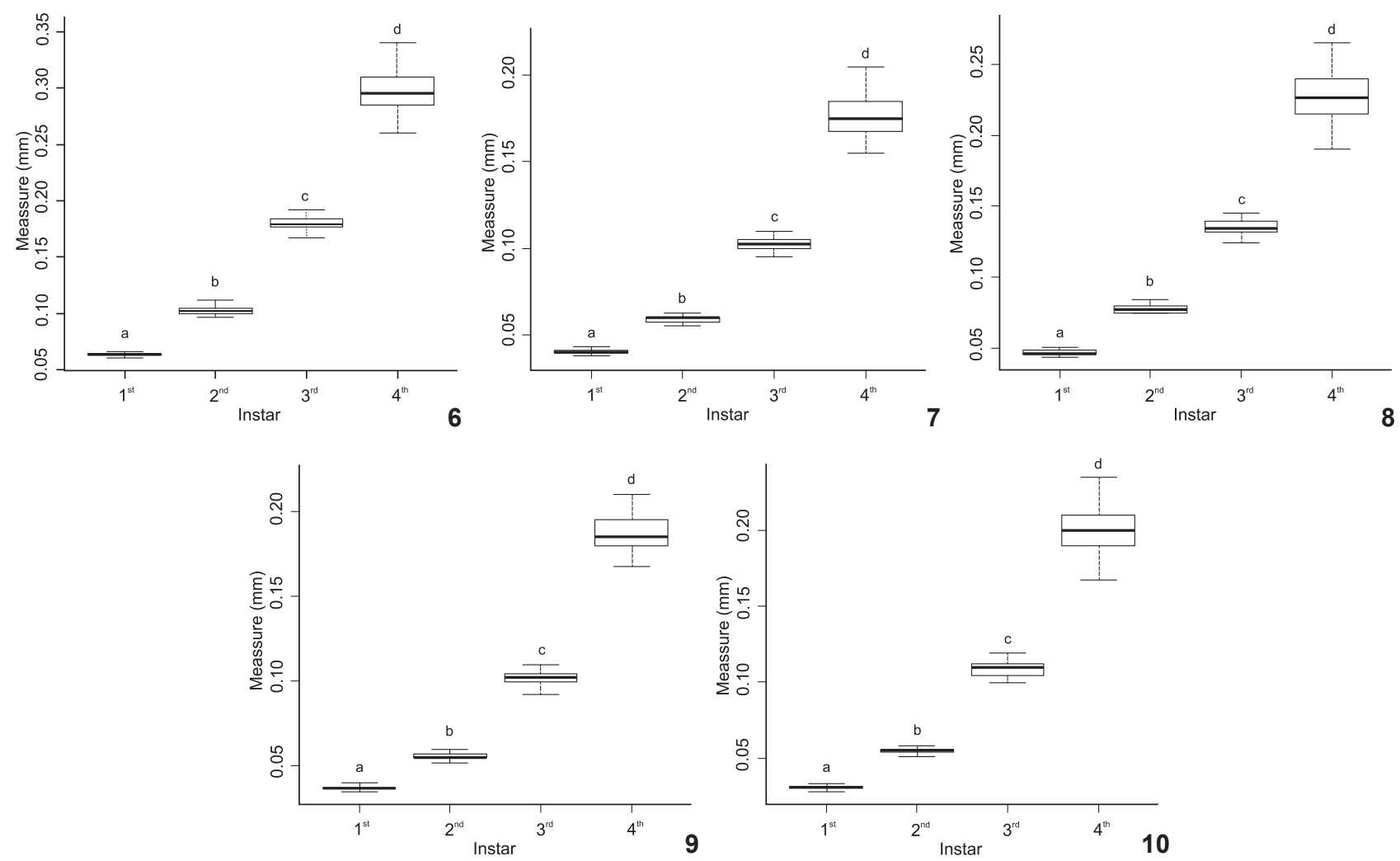

Figures 6-10. Boxplots of the instars by the size of the structures, demonstrating the measures of central tendency and dispersion, different letters indicate significant differences at $p<0.0001$ (One way - ANOVA test followed by Tukey's post test) the measurements of Chironomus sancticaroli head capsule structures: (6) ventral length of head capsule; (7) length of antennae; (8) length of mandibles; (9) length of mentum; (10) length of ventromental plates. 
Table I. Average, minimum, maximum, standard deviation and confidence interval of the size of the head capsule, antennae, mandibles, mentum and ventromental plates of immature of Chironomus sancticaroli kept under laboratory conditions.

\begin{tabular}{lccccccc}
\hline Measures $(\mathrm{mm})$ & Instar & N. larvae & Minimum & Maximum & Mean & SD & Confidence interval \\
\hline \multirow{3}{*}{ Ventral length of head capsule } & I & 27 & 0.061 & 0.066 & 0.064 & 0.001 & $0.0636-0.0644$ \\
& II & 33 & 0.090 & 0.112 & 0.103 & 0.004 & $0.1016-0.1044$ \\
& III & 50 & 0.159 & 0.192 & 0.179 & 0.006 & $0.1773-0.1807$ \\
& IV & 130 & 0.260 & 0.340 & 0.298 & 0.014 & $0.2956-0.3004$ \\
\hline \multirow{3}{*}{ Length of antennae } & I & 27 & 0.037 & 0.044 & 0.040 & 0.002 & $0.0392-0.0408$ \\
& II & 33 & 0.055 & 0.065 & 0.060 & 0.002 & $0.0593-0.0607$ \\
& III & 50 & 0.092 & 0.112 & 0.102 & 0.004 & $0.1009-0.1031$ \\
& IV & 130 & 0.135 & 0.220 & 0.176 & 0.012 & $0.1739-0.1781$ \\
\hline \multirow{3}{*}{ Length of mandibles } & I & 27 & 0.044 & 0.051 & 0.047 & 0.002 & $0.0462-0.0478$ \\
& II & 33 & 0.075 & 0.085 & 0.077 & 0.003 & $0.0759-0.0781$ \\
& III & 50 & 0.119 & 0.145 & 0.135 & 0.006 & $0.1333-0.1367$ \\
Length of mentum & IV & 130 & 0.190 & 0.265 & 0.227 & 0.015 & $0.2244-0.2296$ \\
\hline \multirow{3}{*}{ Length of ventromental plates } & I & 27 & 0.035 & 0.040 & 0.037 & 0.001 & $0.0366-0.0374$ \\
& II & 33 & 0.050 & 0.060 & 0.056 & 0.002 & $0.0553-0.0567$ \\
& III & 50 & 0.092 & 0.112 & 0.103 & 0.004 & $0.1019-0.1041$ \\
& IV & 130 & 0.167 & 0.220 & 0.187 & 0.010 & $0.1853-0.1887$ \\
\hline & III & 27 & 0.028 & 0.033 & 0.031 & 0.001 & $0.0306-0.0314$ \\
& IV & 130 & 0.167 & 0.235 & 0.200 & 0.012 & $0.1979-0.2021$ \\
\hline
\end{tabular}

Table II. Exponential equation of the growth and growth average rate of the head capsule, antennae, mandibles, mentum and ventromental plates of immature Chironomus sancticaroli kept under laboratory conditions.

\begin{tabular}{lcccc}
\hline \multicolumn{1}{c}{ Measure } & Equation $\mathrm{y}=\mathrm{ex}$ & $\mathrm{N}$. larvae & $\mathrm{r}^{2}$ & Average rate of growth \\
\hline Head Capsule & $\mathrm{y}=0.0373 \mathrm{e}^{0.5192 x}$ & 240 & 0.9935 & 1.67 \\
Antennae & $\mathrm{y}=0.0229 \mathrm{e}^{0.5070 x}$ & 240 & 0.9844 & 1.64 \\
Mandible & $\mathrm{y}=0.0275 \mathrm{e}^{0.5275 x}$ & 240 & 0.9895 & 1.69 \\
Mentum & $\mathrm{y}=0.0196 \mathrm{e}^{0.5598 x}$ & 240 & 0.9889 & 1.72 \\
Ventromental plate & $\mathrm{y}=0.0161 \mathrm{e}^{0.6298 x}$ & 240 & 0.9933 & 1.87 \\
\hline
\end{tabular}

the number of striae present on the ventromental plates. This method makes it unnecessary to use morphometric data, as in the present study (Rebechi \& Navarro-Silva 2012). Beyond the length of the head capsule from ventral view, measurements of the antennae, mandibles, mentum and ventromental plates are efficient alternatives for the determination of the larval instars, as found by FoRD (1959) for antennae and mandibles of Clinotanypus nervosus Meigen, 1818; Anatopynia trifascipennis Zetterstedt, 1838 and Procladius choreus Meigen, 1804 and by Frouz et al. (2002) for the mentum of Chironomus crassicaudatus Malloch, 1915 and Glyptotendipes paripes (Edwards, 1929). Among the possible alternatives used, the mentum offers the best option, because it is easy to observe without clearing. It is also difficult to break due to the strong sclerotization. Further- more, if it is necessary to maintain the larva alive, or whole, as in the case of slide mounting, the antennae can be used, as they project beyond the capsule and the entire antennal structure is visible when the larva is positioned laterally. Factors such as the temperature, photoperiod, high population density, quantity and quality of food can alter the development and size of insects (CANTEIRo \& AlberToni 2011). When comparing the results of this study with those obtained by TrivinHoStrixino \& STrixino (1982) for the same species, under different experimental conditions such as temperature $\left(19-26^{\circ} \mathrm{C}\right.$ (ambient)), larval density (100 larvae/pan), photoperiod (ambient), quantity ( $0.4 \mathrm{~g} /$ week) and type of (Avemicina-Purina) food, we found significant differences in the length of the larval development, but the length of the head capsule from ventral view 
was consistent for each instar. Therefore, abiotic factors may influence mainly the duration of the larval stages, but do not affect the dimensions of the head capsule sufficiently that the instars can not be separated. It is likely that these factors also do not affect the the antennae, mandibles, mentum and ventromental plate, and that they can still be used to discriminate instars in the Chironomidae.

Larvae of Chironomus tepperi Skuse, 1889, both in the field and reared in the laboratory at 17.5 and $25.0^{\circ} \mathrm{C}$ (six generations), had head capsules of similar sizes, i.e., temperature variations did not cause a difference in the measurements of the instars. These results suggest that laboratory studies can be applied in the field (STEvens 1993).

In the fourth instar of C. sancticaroli larvae, there is a greater dispersion of values around the average when compared with other instars. This may be due to sexual dimorphism in size, as females are usually larger than males (Ford 1959, Atchley \& Martin 1971, Stevens 1993, Frouz et al. 2002).

All five structures studied on the head capsule of $C$. sancticaroli grow exponentially throughout the larval development. There is no overlap in the dimensions of those structures which allows statistical differentiation between the four instars. Even when the duration of the instars overlapped, those measurements were sensitive enough to detect the desynchronization during the ontogeny of $C$. sancticaroli. These structures make it possible to identify the larval instars even when the cephalic capsule breaks and its proportions become distorted, as well as to use alive or intact larvae.

\section{ACKNOWLEDGMENTS}

We thank Conselho Nacional de Desenvolvimento Científico e Tecnológico (CNPq, process 305038/2009-5).

\section{LITERATURE CITED}

Atchley, W.R. \& J. Martin. 1971. A morphometric analysis of differential sexual dimorphism in larvae of Chironomus (Diptera). Canadian Entomologist 103 (3): 319-327.

Beaudouin, R.; V. Dias; J.M. Bonzom \& A. Péry. 2012. Individualbased model of Chironomus riparius population dynamics over several generations to explore adaptation following exposure to uranium-spiked sediments. Ecotoxicology 21 (4): 1225-1239.

Canteiro, R.C.S.A. \& E.F. Albertoni. 2011. Growth of immature Chironomus calligraphus (Diptera, Chironomidae) in laboratory conditions. Anais da Academia Brasileira de Ciências 83 (4): 1279-1286.

Covich, A.P.; M.A. Palmer \& T.A. Crowl. 1999. The role of benthic invertebrate species in freshwater ecosystems. BioScience 49: 119-28.

Daly, H.V. 1985. Insect morphometrics. Annual Reviews of Entomology 30: 415-438.
Di Veroli, A.; R. Selvaggi \& E. Goretti. 2012. Chironomid mouthpart deformities as indicator of environmental quality: a case study in Lake Trasimeno (Italy). Journal of Environmental Monitoring 14: 1473-1478.

Di Veroli, A.; E. Goretti; C. Marcucci; A. Fabrizi; L. Scopetta \& M.V. Di Giovanni. 2008. Incidence of larvae mouthpart deformities in Chironomus plumosus (Diptera: Chironomidae) and Procladius sp. (Diptera: Chironomidae) from Piediluco Lake, Italy. Boletim do Museu Municipal do Funchal 13: 13-20.

Di Verolli, A.; E. Goretti; M.L. Paumen; M.H.S. Kraak \& W. Admiraal. 2012. Induction of mouthpart deformities in chironomid larvae exposed to contaminated sediments. Environmental Pollution 166: 212-217.

Dyar, H.G. 1890. The number of molts of lepidopterous larvae. Psyche 5: 420-422.

ECole, C.C. 1999. Determinação do número de ínstares larvais em Plutella xylostella (L.) (Lepidoptera: Yponomeutidae). Acta Scientiarum 21: 331-335.

ForD, J.B. 1959. A study of larval growth, the number of instars and sexual differentiation in the Chironomidae (Diptera). Proceedings of the Royal of Entomological Society of London 34 (10-12): 151-60.

FrouZ, J.; A. Aul \& R.J. LobinsKe. 2002. Suitability of morphological parameters for instar determination in pestiferous midges Chironomus crassicaudatus and Glyptotendipes paripes (Diptera: Chironomidae) under laboratory conditions. Journal of the American Mosquito Control Association 18 (3): 222-227.

Frouz, J.; R. Lobinske \& A. Ali. 2009. Intraspecific competition of Glyptotendipes paripes (Diptera: Chironomidae) larvae under laboratory conditions. Aquatic Ecology 43 (2): 487500 .

Henriques-Oliveira, A.L. \& J.L. Nessimian. 2009. Phoresy and commensalism of Chironomidae larvae (Insecta: Diptera) in the state of Rio de Janeiro, Brazil. Lundiana 10 (1): 11-18.

Hutchinson, G.E. \& N. Tongring. 1984. The possible adaptive significance of the Brooks-Dyar rule. Journal of Theoretical Biology 106, 437-439.

KajAK, Z. \& P. Prus. 2001. Effects of the density of larvae and type of substrate on Chironomus plumosus L. (Diptera: Chironomidae) population. Laboratory experiments. Polish Journal of Ecology 49 (4): 369-378.

Maier, K.J.; P. Kosalwat \& A.W. Knight. 1990. Culture of Chironomus decorus (Diptera: Chironomidae) and the effect of temperature on its life history. Environmental Entomology 19 (6): 1681-1688.

McCauley, V.J.E. 1974. Instar differentiation in larval Chironomidae (Diptera). Canadian Entomologist 106: 179-200.

McLachlan, A.J. 1977. Density and distribution in laboratory populations of midge larvae (Chironomidae: Diptera). Hydrobiologia 55 (3): 195-199.

Oliver, D.R. 1971. Life history of the Chironomidae. Annual Review of Entomology 16: 211-230. 
Rebechi, D. \& M.A. Navarro-Silva. 2012. Setting the reference for the use of Chironomus sancticaroli (Diptera: Chironomidae) as bioindicator: Ontogenetic pattern of larval head structures. Zoologia 29 (2): 167-171.

Silva, D.S.; L.A. Kaminski; R. Dell'Erba \& G.R.P. Moreira. 2008. Morfologia externa dos estágios imaturos de heliconíneos neotropicais: VII. Dryadula phaetusa (Linnaeus) (Lepidoptera, Nymphalidae, Heliconiinae). Revista Brasileira de Entomologia 52 (4): 500-509.

Stevens, M.M. 1993. Larval development in Chironomus tepperi (Diptera: Chironomidae) under laboratory conditions. Environmental Entomology 22 (4): 776-780.

Strixino, G. \& S. Trivinho-Strixino. 1985. A temperatura e o desenvolvimento de Chironomus sancticaroli (Diptera: Chironomidae). Revista Brasileira de Zoologia 3 (4): 177-180.

Styczynski, B. \& S. RAKUSA-SusZcZwsKI. 1963.Tendipedidae of selected water habitats of Hornsrund region (Spitsbergen). Polish Archives of Hydrobiology 11: 327-341.

Thienemann, A. 1954. Chironomus. Leben, Verbreitung und wirtschaftliche Bedeutung der Chironomiden. Die Binnengewässer 20: 1-834.

Trivinho-Strixino, S. \& G. Strixino. 1982. Ciclo de vida de Chironomus sancticaroli (Diptera: Chironomidae). Revista Brasileira de Entomologia 26 (2): 183-189.

Trivinho-Strixino, S. 2011. Larvas de Chironomidae. Guia de Identificação. São Carlos, Departamento de Hidrobiologia, Laboratório de Entomologia Aquática, UFSCar, 371p.

U.S. Environmental Protection Agency. 2000. Methods for measuring the toxicity and bioaccumulation of sedimentassociated contaminants with freshwater invertebrates. Washington, DC, Office of Research and Development, EPA/ 600/R-99/064, $2^{\text {nd }}$ ed., 212p.

Submitted: 25.VII.2012; Accepted: 12.XI.2012.

Editorial responsibility: Carolina Arruda Freire 